\title{
Analisa Perbandingan Aplikasi Sistem Satu dan Dua Tingkat Turbocaharger Terhadap Performansi Cummins Engine K38-C
}

\author{
Sofi Purnama, Puji Saksono \\ Program Studi Teknik Mesin Fakultas Teknologi Industri \\ Universitas Balikpapan \\ Jl. Pupuk Raya PO BOX 335 Balikpapan \\ Email : welty1985@yahoo.com; saksono_puji@yahoo.co.id
}

\begin{abstract}
The price of world crude oil is the more expensive making automotive designer that develops the technology of economical fuel engine and the environmental friendliness but it has performance of good engine without altering the size measure or machine dimension. One of the additional peripheral among others by wearing system one and two stage of turbocharger and intercooler

This research is conducted to compare performance of Cummins K38-C family engine with system one and two stage of turbocharger. The examination is conducted by using appliance of dynamometer

Result of from research with rotation of engine is same, two stage system of proven turbocharger can yield performance (power and torque) larger ones if it is compared by the one stage system; that level is various of variation of different load $(0 \%, 25 \%, 50 \%, 75 \%$ and $100 \%$.
\end{abstract}

Key words: Turbocharger stage, rotation of engine, load, performance

\begin{abstract}
Abstrak
Harga minyak mentah dunia yang semakin mahal membuat ahli perancang otomotif mengembangkan teknologi engine yang hemat bahan bakar dan ramah lingkungan tetapi mempunyai performansi engine yang baik tanpa mengubah ukuran atau dimensi mesin tersebut. Salah satu perangkat tambahan diantaranya dengan memakai sistem satu dan dua tingkat turbocharger dan intercooler.

Penelitian ini dilakukan untuk membandingkan performansi Cummins engine K38-C family dengan sistem satu dan dua tingkat turbocharger. Pengujian dilakukan dengan menggunakan alat dynamometer.

Hasil dari penelitian dengan putaran engine yang sama, sistem dua tingkat turbocharger terbukti mampu menghasilkan performansi (daya dan torsi) yang lebih besar jika dibandingkan dengan sistem satu tingkat pada berbagai variasi pembebanan yang berbeda $(0 \%$, $25 \%, 50 \%$, $75 \%$ dan $100 \%$ ).
\end{abstract}

Kata kunci: Tingkat turbocharger, putaran engine, beban, performansi

\section{Pendahuluan}

\subsection{Latar Belakang}

Semakin naiknya harga minyak mentah dunia membuat setiap pabrikan otomotif mengembangkan teknologi pada engine yang hemat bahan bakar dan ramah lingkungan tetapi mempunyai performansi mesin yang baik tanpa mengubah ukuran atau dimensi mesin tersebut.
Pemakaian perangkat tambahan seperti sistem satu dan dua tingkat turbocharger serta intercooler menjadi salah satu solusinya.

Mekanisme sistem satu dan dua tingkat turbocharger serta intercooler digerakkan oleh pemanfaatan gas buang untuk menggerakan turbin dan kompresor. 
Kompresor memampatkan udara ke dalam silinder engine sehingga akan terjadi kenaikan tekanan dan temperatur. Proses kompresi ini menyebabkan berkurangnya nilai kerapatan udara, sehingga diperlukannya suatu alat pendingin (intercooler) yang dapat mendinginkan udara sebelum masuk ke dalam silinder engine.

\subsection{Perumusan dan Batasan Masalah \\ Rumusan masalah dalam} penelitian ini adalah seberapa besar pengaruh penggunaan aplikasi sistem satu dan dua tingkat turbocharger terhadap performansi Cummins engine K38-C ? Adapun batasan masalahnya yaitu bahwa perhitungan diperoleh dari data spesifikasi unit dan hasil data uji pada alat dynamometer.

\subsection{Tujuan dan Manfaat Penelitian}

Penelitian ini bertujuan untuk menganalisa pengaruh aplikasi sistem satu dan dua tingkat turbocharger terhadap performansi Cummins engine K38-C. Sedangkan manfaat penelitian adalah sebagai referensi bagi pemakai produk alat berat tentang pemakaian teknologi engine terbaru.

\section{Tinjauan Pustaka}

\subsection{Turbocharger}

Pada prinsipnya supercharger dan turbocharger mempunyai tujuan yang sama, yaitu memperbesar jumlah udara yang masuk ke dalam silinder. Hal ini bertujuan untuk meningkatkan daya motor tanpa memperbesar kapasitas motor tersebut. Ada perbedaan dalam proses kerja antara supercharger dan turbocharger, yaitu pada penggerak impeller turbin dimana pada supercharger impeller turbin digerakkan oleh gerakan mekanik yang ditransfer dari putaran poros engkol, sedangkan pada turbocharger memanfaatkan gas buang sebagai penggerak impeller turbin.

Sebuah motor diesel empat langkah yang bekerja dengan turbocharger tekanan isapnya lebih tinggi dari tekanan atmosfer sekitarnya. Hal ini diperoleh dengan jalan memaksa udara atmosfer masuk kedalam silinder selama langkah isap. Dengan cara mendinginkan udara bertekanan masuk ke dalam silinder turbocharger dengan aftercooler diharapkan bisa memperoleh tekanan efektif rata-rata yang lebih besar dengan mengurangi turunnya kerapatan udara akibat temperatur yang tinggi. Sehingga akan menghasilkan daya yang lebih besar dengan ukuran mesin yang sama.

Tujuan utama penggunaan turbocharger dengan aftercooler adalah untuk memperbesar daya motor (30-80 \%), boleh dikatakan bahwa mesin diesel dengan turbocharger dapat bekerja lebih efisien, turbocharger mempunyai arti penting dalam usaha mengatasi kerugian daya yang disebabkan oleh berkurangnya kepadatan udara atmosfer di tempat tersebut.

Sistem turbocharger ini digunakkan untuk meningkatkan batas torsi mesin dan tekanan effektif rata-rata. Beberapa mesin tipe $\mathrm{V}$ dan inline menggunakan dua atau empat turbocharger dan aftercooler, masing-masing satu untuk pipa manifold buang. 


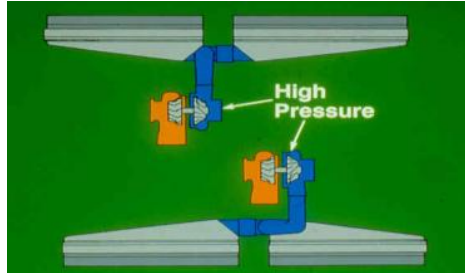

Gambar 1. Konstruksi satu tingkat turbocharger Cummins Engine K38C Family. Sumber: Basic Engine Diesel Cummins, PT. Altrak 1978.

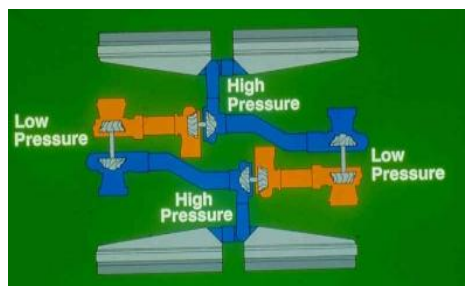

Gambar 2. Konstruksi dua tingkat turbocharger Cummins Engine K38C Family. Sumber: Basic Engine Diesel Cummins, PT. Altrak 1978.

Cara kerja turbocharger dua tingkat: Udara mengalir dari saringan udara ke rumah kompressor tingkat pertama (low pressure turbocharger), kemudian ke luar dari kompresor tingkat pertama dan masuk kompresor tingkat kedua. Setelah dikompres pada kompresor tingkat dua maka udara keluar melewati aftercooler menuju pada pipa manifold hisap silinder. Pada keadaan ini temperatur udara dikurangi sampai $223^{\circ} \mathrm{F} \quad\left(1060^{\circ} \mathrm{C}\right)$ dan dengan tekanan berkisar 60,4 inHG $(204,5 \mathrm{kPa})$. Gas buang hasil pembakaran memasuki pipa manifold tipe pulsa yang kemudian memasuki rumah turbin tingkat dua. Gas buang kemudian meninggalkan turbin tingkat dua dan memasuki turbin tingkat pertama yang akan menggerakkan roda turbin dengan sisa-sisa energi yang terkandung dalam gas buang. Kemudian gas ini dibuang melalui pipa saluran buang ke atmosfir.

\subsection{Intercooler}

Pada saat sekarang ini teknologi otomotif yang sedang berkembang itu adalah intercooler. Alat ini adalah peralatan sederhana di dalam sebuah mobil, tetapi memiliki fungsi yang luar biasa. Intercooler memiliki beberapa nama sebutan antara lain air cooler, after cooler dan charge cooler. Tetapi apapun namanya alat ini memiliki fungsi yang sama yaitu mendinginkan udara yang masuk ke ruang mesin.

\subsection{Daya dan Torsi}

Daya adalah kemampuan melakukan suatu usaha atau kerja dalam setiap satuan waktu tertentu. Sedangkan torsi adalah kemampuan melakukan suatu gerak putar yang besarnya sama dengan perkalian antara gaya dan jarak dari sumbu putar.

\section{Metodologi Penelitian}

\subsection{Tempat dan Waktu Penelitian}

Tempat dilakukannya penelitian di PT. Altrak 1978 Rebuild Center J1. Jend. Sudirman No. 21 Balikpapan.

Sedangkan waktu penelitian dilaksanakan pada bulan Januari s/d Mei 2011.

\subsection{Bahan dan Alat}

Adapun perlengkapan dan alat penelitian yang digunakan adalah:

1. Engine yang di pergunakan dalam penelitian ini adalah Cummins engine diesel $\mathrm{K} 38-\mathrm{C}$ family

2. Turbocharger yang digunakan sebagai penelitian adalah Holset Turbocharger HC5A 
3. Engine dynamometer dengan spesifikasi sebagai berikut:

Tenaga : 2,611 kW (3500 HP)

Torsi : 11,263 ft.lbs $(15,271 \mathrm{Nm})$

Kecepatan : 2800 putaran/menit

Penggunaan air: 255 GPM (16,1 L/s)

(No Cooling system)

Berat : : $620 \mathrm{lbs} .(2,097 \mathrm{~kg})$

Seri/type : DS4010

\subsection{Langkah Penelitian}

Langkah-langkah penelitian adalah sebagai berikut:

1. Engine yang akan di uji performansinya telah melalui proses rebuild engine

2. Turbocharger dipasang pada engine yang diteliti, sebelum dilakukan uji performansi pada engine dynamometer.

3. Memasang kopling dynamometer dengan flywheel. Memasang hose water cooling engine connection, prelube system, fuel dan baterai. Memasang exhaust flange dan muffler. Memasang electrical wiring control. Memasang gauge, oil level, control valve, water pressure pump, stand.

4. Melakukan performansi test dan memeriksa engine saat performansi test dilakukan dengan memeriksa kebocoran pada sekeliling engine. Memeriksa asap buang. Memeriksa ketidaknormal-an bunyi. Memeriksa tenaga yang dihasilkan oleh engine. Melakukan dynotest prosedur sesuai dengan pedoman pengoperasian.

5. Pengambilan data dilakukan pada saat performansi test pada putaran dan variasi beban yang berbeda yang diberikan, data performansi test terlihat pada monitor control.
3.4. Variabel Penelitian

1. Variabel Bebas

- Kecepatan putaran engine [RPM]

- Pembebanan (Load) engine [\%]

2. Variabel Terikat
- Torque Engine
[lb.ft]
- Horse Power Engine
[HP]

3. Variabel control

- Kondisi temperatur air pendingin pada $70^{\circ} \mathrm{C}$.

\section{Hasil Penelitian}

\subsection{Data Hasil Penelitian}

Data penelitian didapatkan dengan cara menguji performansi Cummins engine K38-C sistem satu dan dua tingkat turbocharger pada dynamometer. Pengujian brake in test (torque) engine sistem satu dan dua tingkat turbocharger dimulai dari putaran low idle tanpa diberi beban (load) $0 \%$. Pengujian selanjutnya dengan memberi beban (load) meningkat secara bertahap pada $25 \%, 50 \%, 75 \%$ dan $100 \%$ dari maksimum torque pada torque rating putaran (rpm) engine dengan kondisi temperatur air pendingin pada $70^{\circ} \mathrm{C}$. Dilakukan juga pengujian untuk mendapatkan rated horse power (HP) pada horse power rating putaran engine dengan kondisi $100 \%$ throttle. Sebagai langkah prosedur selanjutnya engine dikembalikan pada kondisi low idle. Lama waktu pengujian pada setiap beban yang diberikan adalah 3-5 menit. Untuk kualitas pengujian engine dilakukan selama 2 jam dengan beban yang diberikan sebesar $80 \%$.

Hasil dari pengujian performansi tercatat pada monitor control dynamometer. Sebagai pemeriksaan akhir hasil pengujian pada dynamometer memeriksa kembali standar paramater engine 
yang didapat dan membandingkan factory. dengan base engine data sheet dari

Tabel 1. Data hasil pengujian Cummins engine K38-C satu tingkat turbocharger

\begin{tabular}{|c|c|c|c|c|r|}
\hline $\begin{array}{c}\text { Load } \\
(\%)\end{array}$ & $\begin{array}{c}\text { Engine } \\
\text { speed } \\
(\mathrm{RPM})\end{array}$ & $\begin{array}{c}\text { Torque } \\
(\mathrm{lb} . \mathrm{ft})\end{array}$ & $\begin{array}{c}\text { Horse } \\
\text { power } \\
(\mathrm{HP})\end{array}$ & $\begin{array}{c}\text { Oil } \\
\text { pressure } \\
(\text { Psi) }\end{array}$ & $\begin{array}{c}\text { Fuel } \\
\text { pressure } \\
(\mathrm{Psi})\end{array}$ \\
\hline 0 & 777.948 & 18.129 & 2.685 & 69.775 & 2.320 \\
\hline 25 & 1500.301 & 1355.732 & 387.273 & 73.051 & 40.010 \\
\hline 50 & 1501.633 & 2037.691 & 582.597 & 65.457 & 68.164 \\
\hline 75 & 1499.617 & 2784.990 & 795.188 & 60.140 & 114.146 \\
\hline 100 & 1801.267 & 2668.532 & 915.201 & 65.229 & 148.996 \\
\hline
\end{tabular}

Tabel 2. Data hasil pengujian Cummins engine K38-C dua tingkat turbocharger

\begin{tabular}{|c|c|c|c|c|c|}
\hline $\begin{array}{c}\text { Load } \\
(\%)\end{array}$ & $\begin{array}{c}\text { Engine } \\
\text { speed } \\
(\mathrm{RPM})\end{array}$ & $\begin{array}{c}\text { Torque } \\
(\mathrm{lb} . \mathrm{ft})\end{array}$ & $\begin{array}{c}\text { Horse } \\
\text { power } \\
(\mathrm{HP})\end{array}$ & $\begin{array}{c}\text { Oil } \\
\text { pressure } \\
(\mathrm{Psi})\end{array}$ & $\begin{array}{c}\text { Fuel } \\
\text { pressure } \\
(\text { Psi) }\end{array}$ \\
\hline 0 & 719.979 & 16.817 & 2.305 & 48.188 & 3.677 \\
\hline 25 & 1400.293 & 2387.282 & 636.486 & 68.598 & 45.153 \\
\hline 50 & 1399.643 & 3588.002 & 956.172 & 66.139 & 90.352 \\
\hline 75 & 1400.954 & 3950.478 & 1053.755 & 61.663 & 105.776 \\
\hline 100 & 1801.974 & 3877.098 & 1330.213 & 71.841 & 143.634 \\
\hline
\end{tabular}

Pada tabel 1 menunjukkan bahwa putaran engine yang dihasilkan sistem satu tingkat turbocharger lebih besar dibandingkan dengan engine sistem dua tingkat turbocharger (tabel 2).
Dari perbedaan putaran engine tersebut dilakukan interpolasi untuk menyamakan parameter putaran sebagaimana dihasilkan pada table 3 berikut ini.

Tabel 3. Data hasil interpolasi Cummins engine K38-C sistem dua tingkat turbocharger terhadap satu tingkat turbocharger.

\begin{tabular}{|c|c|c|c|c|c|}
\hline $\begin{array}{c}\text { Load } \\
(\%)\end{array}$ & $\begin{array}{c}\text { Engine } \\
\text { speed } \\
(\mathrm{RPM})\end{array}$ & $\begin{array}{c}\text { Torque } \\
(\mathrm{lb} . \mathrm{ft})\end{array}$ & $\begin{array}{c}\text { Horse } \\
\text { power } \\
(\mathrm{HP})\end{array}$ & $\begin{array}{c}\text { Oil } \\
\text { pressure } \\
(\mathrm{Psi})\end{array}$ & $\begin{array}{c}\text { Fuel } \\
\text { pressure } \\
(\mathrm{Psi})\end{array}$ \\
\hline 0 & 777.948 & 117.475 & 29.327 & 50.379 & 5.052 \\
\hline 25 & 1500.301 & 2759.133 & 809.637 & 69.407 & 69.733 \\
\hline 50 & 1501.633 & 3661.287 & 1050.991 & 67.584 & 103.858 \\
\hline 75 & 1499.617 & 3932.424 & 1121.772 & 64.167 & 115.090 \\
\hline 100 & 1801.267 & 3881.779 & 1331.803 & 71.835 & 143.797 \\
\hline
\end{tabular}




\subsection{Analisa Perhitungan Daya engine (Horse Power).}

Dari data hasil pengujian pada tabel 1 dan data hasil interpolasi sistem dua tingkat terhadap satu tingkat turbocharger (tabel 3) dapat dihitung daya (horse power) dan momen puntir dengan menggunakan rumus:

$\mathrm{BHP}=\frac{\boldsymbol{T q} \times \boldsymbol{R P M}}{5252}=$

$\mathrm{Tq}=\frac{B H P \times 5252}{R P M}$

Tabel 4. Engine speed vs Horse power

\begin{tabular}{|c|c|r|r|}
\hline \multirow{2}{*}{ Load } & \multirow{2}{*}{$\begin{array}{c}\text { Engine } \\
\text { speed }\end{array}$} & \multicolumn{2}{|c|}{ Horse power (HP) } \\
\cline { 3 - 4 }$(\%)$ & $(\mathrm{RPM})$ & $\begin{array}{c}\text { 1 stage } \\
\text { turbo }\end{array}$ & $\begin{array}{c}2 \text { stage } \\
\text { turbo }\end{array}$ \\
\hline 0 & 777.948 & 2.685 & 17.400 \\
\hline 25 & 1500.301 & 387.282 & 788.181 \\
\hline 50 & 1501.633 & 582.609 & 1046.822 \\
\hline 75 & 1499.617 & 795.205 & 1122.835 \\
\hline 100 & 1801.267 & 915.220 & 1331.325 \\
\hline
\end{tabular}

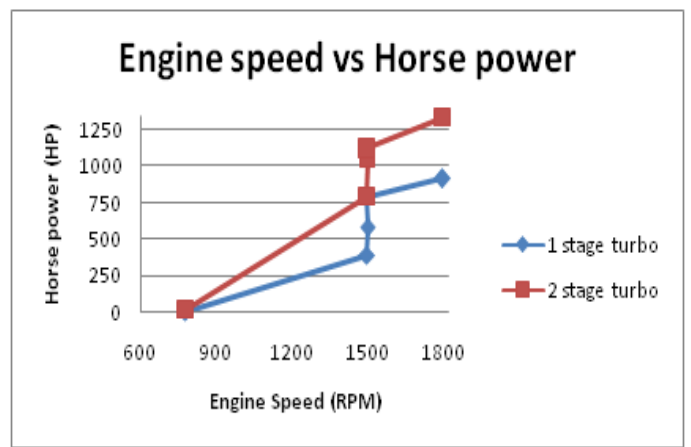

Gambar 3 Grafik Hasil Perhitungan Engine speed vs Horse power

Pada gambar 3 di atas terlihat karakteristik horse power yang lebih baik dengan penggunaan aplikasi sistem dua tingkat turbocharger dibandingkan sistem satu tingkat turbocharger. Tren horse power meningkat seiring dengan naiknya beban (load) dan putaran pada engine.

\subsection{Analisa Perhitungan Momen Puntir (Torque)}

Perhitungan Momen Puntir (Torque) engine sistem satu dan dua tingkat turbocharger sebagai berikut:

Tabel 5. Engine speed vs Torque

\begin{tabular}{|c|c|c|c|}
\hline \multirow[b]{2}{*}{$\begin{array}{c}\text { Load } \\
(\%)\end{array}$} & \multirow{2}{*}{$\begin{array}{l}\text { Engine } \\
\text { Speed } \\
\text { (RPM) }\end{array}$} & \multicolumn{2}{|c|}{ Torque (lb.ft) } \\
\hline & & $\begin{array}{l}1 \text { stage } \\
\text { turbo }\end{array}$ & $\begin{array}{c}2 \text { stage } \\
\text { turbo }\end{array}$ \\
\hline$\overline{0}$ & 777.948 & $\overline{18.126}$ & 197.98 \\
\hline 25 & 1500. & 355.699 & 2834.240 \\
\hline 50 & 1501 & 2037.647 & 367 \\
\hline 75 & 1499.617 & 2784.929 & 3928.700 \\
\hline 100 & 1801.267 & 2668.474 & 3883.171 \\
\hline
\end{tabular}

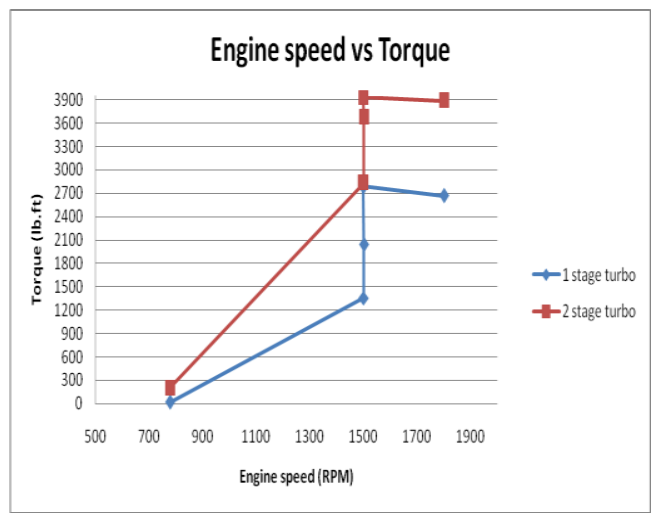

Gambar 4 Grafik Hasil Perhitungan Engine speed vs Torque

Dari gambar grafik 4 menunjukkan bahwa torque yang dihasilkan pada sistem dua tingkat turbocharger lebih baik dibandingkan dengan sistem satu tingkat turbocharger. Tren yang terlihat dari grafik torque meningkat sampai pada 
titik maksimum kemudian menurun. Semakin besar putaran engine tidak selalu menghasilkan torque yang maksimum. Dari hasil pengujian menunjukkan torque maksimum yang dihasilkan kedua sistem satu dan dua tingkat turbocharger terjadi pada putaran 1499.617 rpm. Pada sistem satu tingkat turbocharger menghasilkan nilai torque sebesar 2784,929 lb.ft. Sedangkan sistem dua tingkat turbocharger menghasilkan torque sebesar 3928,700 lb.ft.

\section{Kesimpulan dan Saran}

\subsection{Kesimpulan}

Berdasarkan hasil penelitian yang diperoleh kesimpulan sebagai berikut:

1. Sistem dua tingkat turbocharger menghasilkan momen puntir (torque) dan daya (horse power) yang lebih baik dibandingkan dengan sistem satu tingkat turbocharger.

2. Pada load 0\% putaran 777.948 RPM, sistem dua tingkat menghasilkan daya sebesar 17.400 HP dan 2.685 HP pada sistem satu tingkat. Sedangkan momen puntir yang dihasilkan sistem dua tingkat sebesar 197.989 lb.ft dan 18.126 lb.ft pada sistem satu tingkat.

3. Pada load $25 \%$ putaran 1500.301 RPM sistem dua tingkat menghasilkan daya sebesar 788.181 HP dan 387.282 HP pada sistem satu tingkat. Sedangkan momen puntir yang dihasilkan sistem dua tingkat sebesar 2834.240 lb.ft dan 1355.699 lb.ft pada sistem satu tingkat.

4. Pada load $50 \%$ putaran 1501.633 RPM sistem dua tingkat menghasilkan daya sebesar
1046.822 HP dan 582.609 HP pada sistem satu tingkat. Sedangkan momen puntir yang dihasilkan sistem dua tingkat sebesar 3675.868 lb.ft dan 2037.647 lb.ft pada sistem satu tingkat.

5. Pada load $75 \%$ putaran 1499.617 RPM sistem dua tingkat menghasilkan daya sebesar 1122.835 HP dan 795.205 HP pada sistem satu tingkat. Sedangkan momen puntir maksimal yang dihasilkan sistem dua tingkat sebesar 3928.700 lb.ft dan $2784.929 \mathrm{lb} . \mathrm{ft}$ pada sistem satu tingkat.

6. Pada load $100 \%$ putaran 1801.267 RPM sistem dua tingkat menghasilkan daya maksimum sebesar 1331.325 HP dan 915.220 HP pada sistem satu tingkat. Momen puntir yang dihasilkan sistem dua tingkat sebesar 3883.171 lb.ft dan 2668.474 lb.ft pada sistem satu tingkat.

\subsection{Saran}

1. Melaksanakan standar operation procedure (SOP) selama proses rebuild engine untuk mendapatkan kualitas maksimal pada saat pengujian di atas dynamometer.

2. Perlu dilakukan penelitian lanjutan tentang efisiensi engine, emisi gas buang serta nilai ekonomis dari aplikasi kedua jenis tingkat turbocharger tersebut.

\section{Daftar Pustaka}

Holset, 1996, Repair Manual Holset Turbocharger HC5A, Second Edition. Holset, United Kingdom (UK). 
Altrak 1978 PT., 2010, Basic Engine Diesel Cummins, PT. Altrak 1978, Balikpapan.

Altrak $1978 \quad$ PT., 2010, Pembangkitan Daya Engine Diesel 4 Tak, PT. Altrak 1978, Balikpapan.

Arismunandar, W, dan Tsuda, K, 2004, Motor Diesel Putaran Tinggi, Cetakan Kesepuluh, Pradya Paramitha, Jakarta.

Arismunandar Wiranto, 2004, Penggerak Mula Motor Bakar Torak, Cetakan Keempat, ITB Bandung, Jakarta.
Edward F. Obert, 1996, Internal Combustion Engine, third edition, Scranton, Pennsylvania.

Petrovsky, N, 1988, Marine Internal Combustion Engine, Mir Publisher, Moscow.

http://www.google.com/Introductio n, Exhaust, and Turbocharger System Principle.

http://www.cummins.com. 